DIW BERLIN

Discussion

Papers
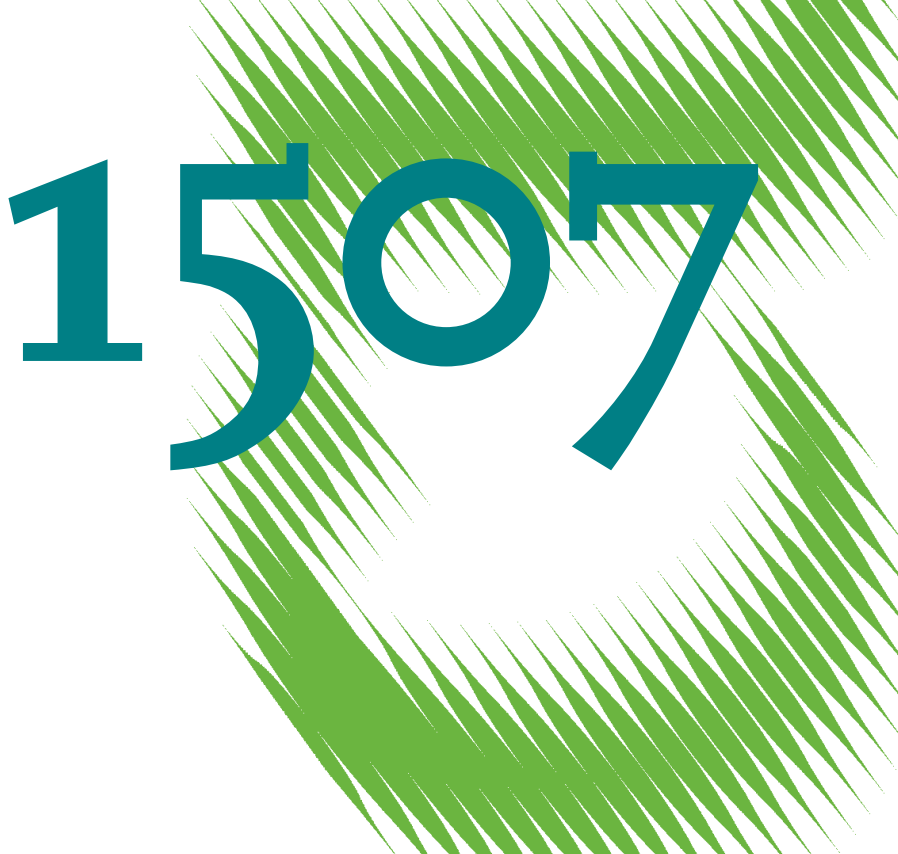

When Low Market Values Are No

Bad News: On the Coordination of

Renewable Support and Real-Time Pricing 
Opinions expressed in this paper are those of the author(s) and do not necessarily reflect views of the institute.

IMPRESSUM

(C) DIW Berlin, 2015

DIW Berlin

German Institute for Economic Research

Mohrenstr. 58

10117 Berlin

Tel. +49 (30) $89789-0$

Fax +49 (30) $89789-200$

http://www.diw.de

ISSN electronic edition 1619-4535

Papers can be downloaded free of charge from the DIW Berlin website:

http://www.diw.de/discussionpapers

Discussion Papers of DIW Berlin are indexed in RePEc and SSRN:

http://ideas.repec.org/s/diw/diwwpp.html

http://www.ssrn.com/link/DIW-Berlin-German-Inst-Econ-Res.html 


\title{
When low market values are no bad news: On the coordination of renewable support and real-time pricing
}

\author{
Michael Pahle ${ }^{*}, \#$, Wolf-Peter Schill ${ }^{* *}$, Christian Gambardella ${ }^{*}$, Oliver Tietjen ${ }^{*}$
}

\begin{abstract}
We analyze the interactions between different renewable support schemes and the benefits of real-time pricing (RTP) using a stylized economic model with a detailed demand-side representation calibrated to the German market. We find that there are considerable differences between a market premium on energy and capacity regarding wholesale prices, support levies and market values, which are all related to induced negative wholesale prices in case of the former. This comes along with overall higher welfare as it allows RTP consumers to increase their consumption in periods of high renewable availability. Moreover, increasing RTP shares also incurs higher welfare gains in case of a premium on energy, with the deployment-relevant group of consumers that switch from a flat-rate tariff to RTP benefiting most. Our analysis thus puts the widespread notion that higher market values are instrumental for the deployment of high shares of RES into perspective.
\end{abstract}

JEL: D02; Q21; Q28; Q42; Q58

Keywords: RES support schemes, demand side response, market value, negative prices, Germany

We thank the participants of the Berlin Conference on Energy and Electricity Economics 2015 for valuable comments. We also thank Stiftung Mercator and Agora Energiewende for funding this research as part of the project "A Renewable Energy Dominated Power Market: Challenges \& Solutions for Market Design and Policy Instruments". The views expressed here are our own.

\footnotetext{
*Potsdam Institute for Climate Impact Research (PIK), Telegrafenberg, 14473 Potsdam

**German Institute for Economic Research (DIW Berlin), Mohrenstr. 58, 10117 Berlin. wschill@diw.de.

\#Corresponding author. Contact: Phone: ++49-331-288 2465, Email: michael.pahle@pik-potsdam.de.
} 


\section{Introduction}

Many countries around the world strive for high shares of renewable energy sources (RES) in their power systems, and fluctuating RES like wind power and solar photovoltaics are likely to make up a major share of it in most of them. Increasing their share however confronts policy-makers with various challenges (see Edenhofer et al. 2013). In this paper, we deal with two particularly important ones: First, power systems have to become sufficiently flexible to cope with the specific characteristics of fluctuating RES. Second, existing support schemes need to be designed such that these technologies can increasingly be integrated into power markets.

Flexibility is necessary in order to balance demand and increasingly fluctuating supply at all times. In that respect additional flexibility can have different values for the power system, for example by reducing peak generation capacity requirements, increasing the utilization of low-cost generation technologies, and reducing residual load gradients. In particular, in times of high demand and scarce supply, additional flexibility can help to reduce demand and by extension avoid black outs. Flexibility can also be instrumental for increasing RES generation through the opposite effect, i.e. by increasing demand in times of high RES generation and thus reducing potential curtailment. Several technical options for flexibility are available, including energy storage, supply-side flexibility, and various demand-side measures (Lund et al. 2015). While a mix of different flexibility options may lead to cost-efficient outcomes in future scenarios with high shares of RES (Zerrahn \& Schill 2015a), in particular demand-side flexibility seems to be at the center of current interest. The European Commission (European Commission 2015) also highlights the importance of demand-side flexibility in its consultation on the new energy market design, stating that "demand response will further contribute to the flexibility required to integrate renewable energy into the market". In Germany, the white book published by the Government (BMWi 2015b) also underlines the role of flexibility to that end.

The second major challenge is how increasing shares of RES can be integrated into the market. Many existing RES support schemes, in particular feed-in tariffs, are designed such that RES generators do not face the power price and its fluctuations. A main motivation for doing so was to shield RES generators from investment risks in order to facilitate access to finance for a broad range of investors. Moreover, price risks may result in higher financing costs of renewable projects (Gawel \& Purkus 2013). However, an increasing exposure to power prices and respective risks creates incentives for RES generators to design and operate plants more efficiently and thus reduce system costs, which is all the more important the higher the share of RES (see Klessmann et al. 2008; Pahle \& 
Schweizerhof 2015). Accordingly, different instruments are needed to eventually accomplish market integration.

This issue has gained particular importance in Germany, where the share of - mostly fluctuating RES in power consumption has exceeded $25 \%$ in 2014 , and a long-term target of at least $80 \%$ by 2050 is in place. The current government has already taken first steps in this direction by making direct marketing mandatory for large new generators, but the question of a suitable support scheme for ever-growing shares of RES is still unresolved. The most prominent options considered so far in Germany are a market premium on energy and a market premium on capacity. While the first is currently envisaged by the German government (BMWi 2015a), the latter was prominently put forward by Enervis \& BET (Enervis \& BET 2013) and Agora Energiewende (2014), in the case of the latter inter alia based on the motivation that it does not distort prices in comparison to a premium on energy, which incentivizes generation even at negative market prices.

So specifically - albeit not exclusively - in Germany, policy-makers need to make two important decisions: (a) if and how to make in particular the demand-side more flexible, and (b) which instrument to use to integrate RES into the market. There is a need to coordinate these decisions, because there is an interaction between flexibility requirements and the choice of the support instrument. More precisely, different support instruments have distinct effects on power prices. Power price fluctuations, however, have an impact on the value of increased demand-side flexibility. Hence, broadly speaking, the market integration strategy and the flexibility strategy need to be coordinated.

Against this background, this paper analyzes the interaction between support instrument choice and flexibility based on a stylized numerical example calibrated to the German case. We adopt a mediumterm perspective and specifically look at a RES share of $50 \%$ planned to be achieved in Germany by 2030, which is often considered as an important milestone on the way to a RES-dominated power market. Regarding flexibility, we focus on demand side response (DSR). ${ }^{1}$ It appears that DSR is underresearched compared to other flexibility options. In particular, while there is yet considerable evidence for demand response to very high prices, see for example Faruqi \& Sergici (2010) and Wolak (2011), the question on how demand responds to very low or even negative prices is essentially unanswered, and research in this direction as ours must rely on standard assumptions - an important issue that we will address further later on. Furthermore, unlocking DSR potentials requires removing political, technical and infrastructural barriers (Cappers et al. 2012), which certainly incurs costs.

\footnotetext{
${ }^{1}$ There are different types of DSR, for example, load shifting between periods or temporary load shedding. Here, we consider an alternative form of demand-side flexibility, i.e. an increased share of demand being exposed to real-time prices, which results in a more price-elastic aggregate demand.
} 
Considering that DSR does not come without costs the question arises under which RES support scheme the value of increasing demand-side flexibility is higher.

Methodologically our work relates to two strands of literature. The first one is on the price effects of high shares of RES, which on a general level is analyzed for example by Sensfuß et al. (2008), Green \& Vasiliakos (2011) and Bushnell (2011). A more specific aspect is that the market value of RES tends to decline with increasing shares, as for example analyzed by Joskow (2011) and Hirth (2013). It is a widespread notion that decreasing market values are detrimental to higher RES shares. This paper aims to contribute to the respective literature by putting just this into perspective. Another aspect relates to negative prices arising from higher RES shares, in particular if induced by RES support. Such prices are considered as controversial - some view them as distortions (see above) while others point out that respective underlying bids by RES generators merely reflect potentially forgone support payments; see for example Nicolosi (2010), Perrez-Arriga \& Battle (2012) and De Vos (2015). In line with Perrez-Arriga \& Battle's (2012) call for a more careful examination of the link between negative prices a and renewable support schemes this paper aims to make another contribution by underlining the value of negative prices specifically in relation to demand side response. The second strand of literature is the analysis of the value of increasing DSR in the power system. In particular there is a series of papers that all draw on the framework developed by Borenstein \& Holland (2005), for example Alcott (2012) and Gambardella et al. (forthcoming). The latter is actually a companion paper to this article focusing on the welfare effects of DSR in the context of high shares of renewables and $\mathrm{CO}_{2}$ pricing.

The paper closest to ours in terms of intention and approach is probably Mills \& Wiser (2015), who evaluate the economic value of different flexibility options for California. We however differ from this study in at least three ways: (a) we explicitly consider different RES support instruments and their respective price effects, (b) we explicitly focus on the demand side and do so in greater detail, and (c) we study the case of Germany, which as California is also an international front-runner in the deployment of fluctuating RES.

That said we want to stress that this paper explicitly does not entail normative considerations about instrument choice. In particular we leave out carbon pricing here, even though - if avoiding GHG emissions is the primary or only objective - it would be the efficient economic instrument. Moreover, it is also important to point out that the support schemes we analyze differ with regard to the incentives they create. The market premium on capacity for example has been criticized based on past experiences that investors had focused on just putting "steel-in-the-ground" rather than on optimizing output (Boute 2012). So while we consider different instruments as policy options and 
only look at specific economic aspects, the overall efficiency of these instruments is another question beyond the scope of this paper.

The remainder of this paper is structured as follows: In section 2 we describe the general approach, the model and the parameters used. In section 3 we present the results of the base case and sensitivity analyses. In section 4 we discuss potential distortions due to model limitations. The final section concludes.

\section{Methodology}

\subsection{General approach}

The overall analysis follows a two-stage approach. In the first stage, we use a stylized power market model with endogenous investments assuming profit-maximizing generators and utility-maximizing consumers. The model includes the two market-based RES support instruments discussed above, i.e. premiums on energy or capacity. These are set to induce a RES share of $50 \%$. We compute the respective long-term equilibria for increasing levels of DSR, or more precisely, for different shares of consumers with real-time pricing (RTP) tariffs. We start with an RTP share of $10 \%$ (base case) and exogenously increase it in equidistant steps up to $50 \%$, resembling counterfactual "what-if" policy scenarios. Such an approach - which only considers benefits and not costs of DSR - is widespread in the literature and has been used for example by Alcott (2012) in the context of demand-side flexibility and capacity markets. In particular, it is helpful to gain insights about the benefit curve of increased DSR rather than just the marginal benefits, i.e. how much does welfare increase if DSR is raised to higher levels.

In the second stage, we explore the value of increased DSR under each of the two instruments. This is done by calculating welfare changes between scenarios with different RTP shares. We also study the distribution of welfare effects between different consumer groups. This is done by separating the rents of consumers with RTP tariffs, flat-rate pricing (FRP) tariffs, and such consumers who switch between the two tariffs. In doing so, we are able to determine under which instruments DSR improvements are most valuable. Moreover, as welfare changes in a long-term competitive equilibrium fully relate to changes in consumer surplus, they are also indicative for the incentives of consumers to switch to RTP.

\subsection{Stage 1: Model and parameters}

We employ a long-term power market model with endogenous investments similar to Pahle et al. (2013) using one representative year, assuming a long-run competitive equilibrium and perfect 
foresight of all market participants. For a given level of the respective RES support instrument, i.e. specific values of energy- or capacity-related premiums, the equilibrium with respect to dispatch and investment is formulated as a Mixed Complementarity Problem (MCP). This MCP constitutes the lower level problem of a Mathematical Program with Equilibrium Constraints (MPEC), the upper level of which is represented by the regulator's problem of setting welfare-optimal levels of the respective RES support instrument. The MPEC is implemented in GAMS and solved with the commercial solver NLPEC. $^{2}$ The full model formulation and a list of all sets, parameters and variables (Table 7) are provided in the Appendix. In the following, we highlight the equations that differ from the abovementioned framework.

Our analysis is calibrated to a hypothetical German market in 2030 with a RES share of $50 \%$ of RES. We thus use a semi-stylized approach that aims to capture essential characteristics of the German market (see below) while not going to deep into current market details. In particular, we use a greenfield approach that does not consider current existing capacities. Moreover, we ignore trade with neighboring markets and more technical issues like start-up costs and ramping constraints. We omit these features in order to reduce numerical complexity and keep the MPEC solvable. The directions in which the results may be distorted due to various simplifications are discussed in section 4.

\subsubsection{Supply side}

Generators maximize profits by choosing appropriate generation capacities and hourly dispatch levels. We consider three representative thermal technologies (base, mid, peak) and two variable renewable technologies (wind onshore, solar PV). The thermal technologies correspond to hard coal (base), natural gas combined cycle gas turbines (CCGT, mid), and oil-fired open cycle gas turbines (OCGT, peak), respectively. While this selection is certainly stylized, it covers the relevant spectrum of technology options with respect to the relation of fixed and variable costs (Table 1). The cost parameters have been calculated drawing on techno-economic parameters provided in Schröder et al. (2013) and fuel price scenarios of the 2014 IEA World Energy Outlook.

Table 1: Fixed and variable costs of generation technologies

\begin{tabular}{lcc}
\hline & $\begin{array}{c}\text { Annuitized fixed costs }\left(\boldsymbol{f} \boldsymbol{c}_{\boldsymbol{i}}\right) \\
{\left[€ /\left(\mathrm{kW}^{*} \mathrm{a}\right)\right]}\end{array}$ & $\begin{array}{c}\text { Variable costs }\left(\boldsymbol{m} \boldsymbol{c}_{\boldsymbol{i}}\right) \\
{[€ / \mathrm{MWh}]}\end{array}$ \\
\hline Wind & 136 & 0 \\
PV & 76 & 0 \\
Base (hard coal) & 125 & 34 \\
\hline
\end{tabular}

\footnotetext{
${ }^{2}$ The GAMS code and all input parameters are available from the authors upon request.
} 


\begin{tabular}{lcc}
\hline Mid (CCGT) & 89 & 64 \\
Peak (OCGT oil) & 40 & 174 \\
\hline
\end{tabular}

On the RES side, we focus on the two most prominent fluctuating technologies, as these are very likely to contribute most to Germany's renewable targets. In particular, we leave out wind offshore and biomass because of higher costs and restricted potentials. ${ }^{3}$ Hourly RES availability factors are calculated from German 2013 market data. Annual average capacity factors are 18\% (wind onshore) and $10 \%$ (solar PV), respectively.

\subsubsection{Instruments for RES support}

We consider two market-based instruments: a fixed technology-neutral market premium on energy $\left(m p^{q}\right)$ and a fixed, technology-specific market premium on capacity $\left(m p_{i}^{c}\right)$. The latter is adjusted for yearly production, such that it can also be considered technology-neutral. The premium on capacity is certainly the least established scheme and thus requires further explanation of the fundamental design element, i.e. how to set the premium. The main issue here is that different RES have different production profiles and in particular different capacity factors. A single technology-neutral premium would thus overpay technologies with low capacity factors. Accordingly, the premium should be multiplied by a production-specific coefficient, i.e. the capacity factor, so that eventually the premium on capacity is identical to a premium on expected production.

The instruments are implemented in the model as follows: The premium on energy $\left(m p^{q}\right)$ is an additional payment for every produced unit of electricity and thus enters the first order condition with respect to power generation from RES in the following way:

$$
0 \leq m c_{i}-m p^{q}+\lambda_{i, t}-\mathrm{p}_{\mathrm{t}} \perp \mathrm{q}_{i, t} \geq 0 \quad \forall i \in I R, t
$$

From this condition one can already see that there is a production incentive for RES generators even if the price is negative. More precisely, under the assumption that marginal costs of RES are zero they produce up to the point where the price equals the negative market premium.

The premium on capacity $\left(m p_{i}^{c}\right)$ is an additional payment for every installed unit of RES capacity and thus enters the first order condition for investment in the following way:

\footnotetext{
${ }^{3}$ Explorative model runs that include these technologies indicate that the computation time increases substantially without changing qualitative results.
} 


$$
0 \leq f c_{i}-m p_{i}^{c}-\sum_{T} \lambda_{i, t} a v_{i, t} \perp K_{i} \geq 0
$$

$\forall i \in I R$

From the generator's perspective, the level of both support instruments is an exogenous parameter. Requiring both instruments to exactly achieve a RES share of $50 \%$ implicitly introduces another agent, namely the regulator whose decision problem is to set the instrument level accordingly. This is explained further in section 2.2.4.

Both market premiums are assumed to be financed by a levy that is paid by all consumers. Importantly, the levy is assumed to be equally attributed to every unit of energy consumed, i.e. it does not depend on the time of consumption or the type of consumer. The levies are determined as described by equations ( $8 \mathrm{a}$ ) and (8b) in the Appendix.

\subsubsection{Demand side}

In contrast to the various simplifications on the supply side, we use a more realistic representation of the demand side than typically found in power market models. Based on the framework by Borenstein \& Holland (2005), we split consumers in two segments: flat-rate pricing consumers facing an annual average price $\bar{p}$, and consumers with real-time pricing that are dynamically priced with $p_{t}$. This is done by including an additional retail market in the model and partitioning total demand $\left(Q_{t}\right)$ in an RTP share $(\alpha)$ and an FRP share $(1-\alpha)$.

$$
Q_{t}\left(p_{t}, \bar{p}, l\right)=\alpha Q_{t}\left(p_{t^{\prime}} l\right)+(1-\alpha) Q_{t}(\bar{p}, l) \quad \forall t
$$

Regarding the current share of RTP consumers in the German market there is a considerable lack of data. The latest monitoring report by the German regulator only provides data about consumers with metering infrastructure, but not about pricing schemes that need not to be disclosed to the public. Agora Energiewende (2015) uses an exemplary bid curve to illustrate that a certain share of demand is already responsive to prices (around $3 \mathrm{GW}$ at the respective hour), but that does not allow to make a qualified estimate. Accordingly, we assume $\alpha=10 \%$, which is roughly in line with others markets like PJM (see Allcott 2012). Furthermore we take demand to be a function of the total consumer price, i.e. the power price plus the levy for RES payments. For doing so, we assume that the retailer procures renewable power or capacity from respective producers and passes on costs to consumers without any exemption. 
Finally, we assume demand to be a linear function of the respective price. We calculate the slope $(m)$ using a price elasticity of -0.05 and weighted annual average prices and quantities, drawing on German market data of the year 2013. While both the functional form and the value of price elasticity are conventions supported by the literature, there is little evidence on the shape of demand functions for any consumer type. Green \& Vasiliakos (2010) also use a linear function, but Bushnell (2011) for example uses a partial log-function and Borenstein \& Holland (2005) an isoealstic function. Likewise, parameters for demand elasticity also vary. Both Bushnell (2011) and Borenstein \& Holland (2005) use the same value we do, whereas Green \& Vasiliakos (2010) employ higher values (-0.2 and -0.3). Other work like Pineau \& Murto (2003) uses even higher values (-0.4). Given that modelled prices very much depend on the assumed functional form and parametrization of demand, we discuss the effect of alternative assumptions as part of a sensitivity analysis.

\subsubsection{The regulator's problem}

On the upper level of the MPEC, we assume a regulator to maximize welfare by choosing optimal levels of the energy- or capacity-related market premiums. Its objective function is as follows:

$$
\begin{gathered}
\max w f=\sum_{T}\left[\alpha\left(\frac{\left(\mathrm{p}_{\mathrm{t}}+\text { levy }\right)^{2}}{2 m}-\frac{p 0_{t}-\mathrm{p}_{\mathrm{t}}}{m}\right)+(1-\alpha)\left(\frac{(\bar{p}+\text { levy })^{2}}{2 m}-\frac{p 0_{t}-\bar{p}}{m}\right)\right] \\
-\sum_{I, T} m c_{i} \mathrm{q}_{i, t}-\sum_{I} f c_{i} K_{i}
\end{gathered}
$$

This is solved subject to the renewable target constraint and the lower-level market equilibrium, all provided by equations (2) to (8) in the Appendix.

Commercial MPEC solvers are still not very advanced and come along with many numerical challenges. Yet it turns out that this bi-level model can be solved properly if the starting values are close enough to the final solution. Hence in order to solve the MPEC, an appropriate parameter level of the respective market premium suitably close to the final solution has to be found by trial and error.

\subsection{Stage 2: Ex-post calculation of welfare effects}

In this paper we focus on the welfare effects of increasing RTP shares. These depend on wholesale prices, which in general differ for the two instruments. Accordingly, for each model run with varying RTP shares, we compute the welfare changes, building on prices and quantities obtained from the model runs in Stage 1. These welfare changes must not be understood as an economic quality of the underlying instrument in the sense that higher values necessarily reflect a more efficient market outcome. They merely indicate the value of increasing DSR under the different RES support schemes. 
As described above we consider flexibility as the activation of demand response by means of consumers switching from flat-rate pricing to real-time pricing. That is, such switching consumers are assumed to have been in principle responsive to price changes all along, but were not previously exposed to it primarily due to a lack of smart metering infrastructure. It is important to distinguish this kind of DSR from other kinds of DSR which presuppose that consumers already face varying prices, for example the adaptation of manufacturing process by industrial consumers.

We assume that the incentive for consumers to change from FRP to RTP derives from the opportunity to increase their surplus. More precisely, in times when the real-time price is lower than the flat-rate price, they will consume more and thus increase surplus. This of course is partially offset in times when the real-time price is higher. Accordingly, we compute surplus changes between model runs with different RTP shares, say $\alpha_{0}$ and $\alpha_{1}$, for different types of consumers. It should be noted that the changes in consumer surplus also constitute the respective overall welfare changes, as producer rents are always zero in the long-run equilibrium modeled here. The surplus change of incumbent FRP consumers, i.e. consumers that face a flat-rate price for both values of $\alpha$ considered, is calculated as follows

$$
\Delta C S^{F R P}=\sum_{T} \frac{\left(1-\alpha_{1}\right)}{m}\left[\left(\frac{\bar{p}_{0}^{2}}{2}-p 0_{t} \bar{p}_{0}\right)-\left(\frac{\bar{p}_{1}^{2}}{2}-p 0_{t} \bar{p}_{1}\right)\right]
$$

The surplus change of incumbent RTP consumers, i.e. consumers that face real-time prices for both values of $\alpha$ considered, is calculated respectively:

$$
\Delta C S^{R T P}=\sum_{T} \frac{\alpha_{0}}{m}\left[\left(\frac{p_{t_{0}}^{2}}{2}-p 0_{t} p_{t_{0}}\right)-\left(\frac{p_{t_{1}}^{2}}{2}-p 0_{t} p_{t_{1}}\right)\right]
$$

Finally, the surplus of those consumers that switch from FRP to RTP is as follows:

$$
\Delta C S^{S W I T C H}=\sum_{T} \frac{\left(\alpha_{1}-\alpha_{0}\right)}{m}\left[\left(\frac{\bar{p}_{0}^{2}}{2}-p 0_{t} \bar{p}_{0}\right)-\left(\frac{p_{t_{1}}^{2}}{2}-p 0_{t} p_{t_{1}}\right)\right]
$$

In face of the many complexities on the demand side this rather simple approach requires further discussion. A first issue is that demand response not only includes reducing and increasing demand within an hour, but also shifting demand over hours. In engineering-oriented dispatch models with price-inelastic demand, such shifts can in principle be modeled by using appropriate constraints (see Zerrahn \& Schill 2015b). Yet in economic models with price-elastic demand, a proper representation of load shifts is more challenging (see De Jonghe et al. 2014). The relevant behavioral parameter is 
cross-price elasticity, which is typically measured between peak, off-peak and sometimes also shoulder periods; see Faruqui \& Sergici (2010) for a review of studies. However, prices in a market with high RES shares do not exhibit the traditional price patterns (peak, off-peak) anymore. Rather, prices may fluctuate considerably by the hour or stay constant over many hours. Hence due to uncertain and highly speculative parametrization of cross-price elasticity in a future setting with high shares of RES, we do not explicitly model demand shifting in this analysis. Instead, we focus on ownprice elasticity, which in any case should lead to comparable outcomes with respect to load reductions in high-price periods and load increases in low-price hours.

A second issue refers to the question if consumers are truly as responsive to price changes as typically assumed in economic models. In particular it has been doubted that lower prices lead to steadily increasing consumption levels. In fact, most research so far like for example by Wolak (2011) focusses on DSR in times of peak prices (price spikes). Recent research by Lang \& Okwelum (2015) on off-peak behavioral responses however confirms that consumption indeed increases in off-peak times because load is being shifted, at least partly, from peak times.

\section{Results}

\subsection{Effects on prices and quantities}

We first look at the base case $(\alpha=10 \%)$ under the default demand assumption (linear functional form and $\varepsilon=-0.05$ ). As for quantities, both capacities (Figure 1) and generation only marginally differ between the premium on energy $\left(m p^{q}\right)$ and on capacity $\left(m p_{i}^{c}\right)$. This hardly changes if the RTP share is increased. Common to both instruments however is a decreasing deployment of peaker capacity up to the point of no capacity at all at $\alpha=50 \%$. Moreover, mid capacity is also reduced, down to $75 \%$ of its original size at the same value of $\alpha$. The explanation for this is relatively straight forward: demand flexibility has the strongest impact when prices are high, i.e. in times of peak demand. Consequently, respective demand reductions lower the profitability of peaker plants, which is why investments are lower. 

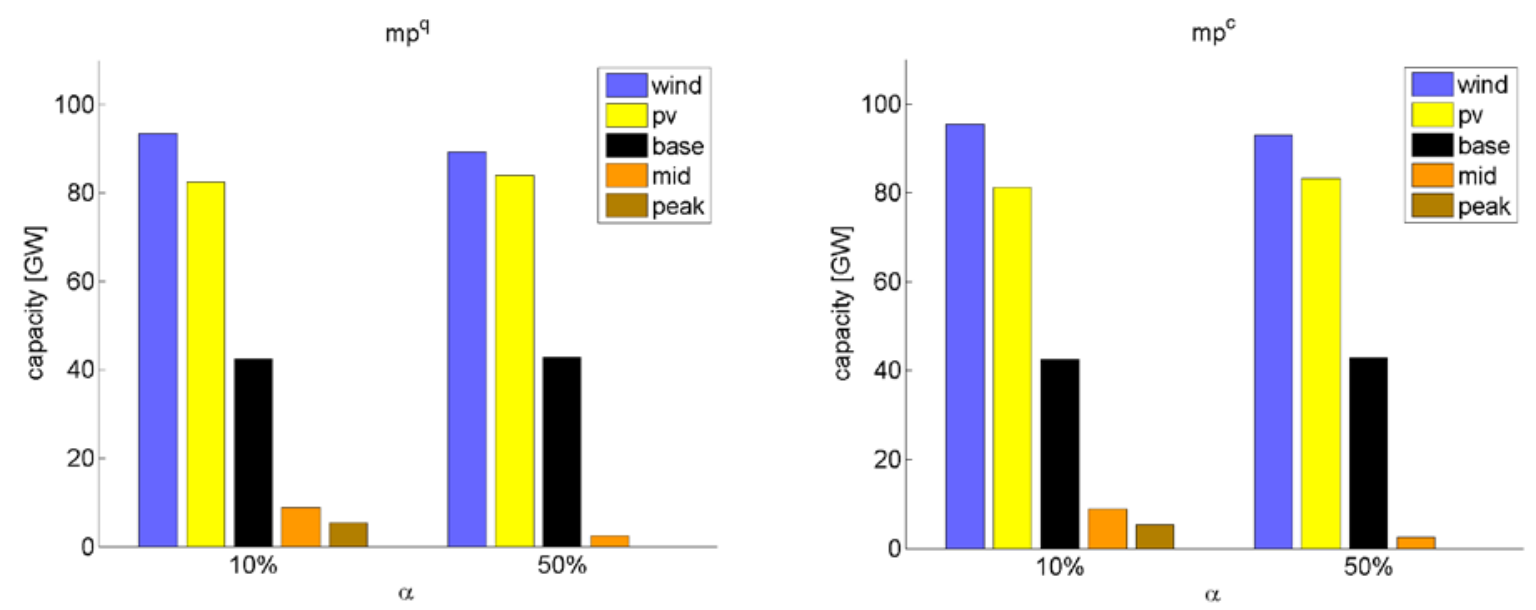

Figure 1: Equilibrium capacities for RTP shares of $10 \%$ and $50 \%$

When looking at prices though considerable differences turn up (Table 2). The average wholesale price $^{4}$ in case of a premium on energy is much lower (around $37 € / \mathrm{MWh}$ for $\alpha=10 \%$ ) compared to a premium on capacity ( $48 € / \mathrm{MWh}$ ). This is because the premium on energy creates incentives to produce at negative prices up to the negative value of the premium. This happens in around 1200 hours for $\alpha=10 \%$ (1100 hours for $\alpha=50 \%$ ) and consequently lowers the average price. Accordingly, overall support payments ( $18.8 \mathrm{bn} €$ compared to $14 \mathrm{bn} €$ ) must be higher in the case of a premium on energy as compared to a premium on capacity, which is also reflected in higher levies paid by consumers ( $43 € / M W h$ vs. $32 € / M W h$ ). Importantly, the sum of average wholesale prices and levies and thus the overall price paid by consumers is roughly equal ( $80 € / \mathrm{MWh})$ in both cases, which should be the case given that capacity mixes and plant utilization are very similar. Hence the main effect of the market premium on energy - in comparison to the premium on capacity - is a value transfer from the good "power" to the good "green". This hardly has an effect on fossil capacities because in the hours with negative prices residual demand is zero, i.e. fossils do not sell to the market in either case. Accordingly, in our setting they relate to the support scheme and only occur when residual demand is zero.

Table 2: Comparison of prices

\begin{tabular}{ccccc}
\hline & $\alpha$ & $\begin{array}{c}\text { Avg. wholesale } \\
\text { price [€/MWh] }\end{array}$ & $\begin{array}{c}\text { Levy } \\
{[€ / \mathrm{MWh}]}\end{array}$ & $\begin{array}{c}\text { Retail price } \\
\text { [€/MWh] }\end{array}$ \\
\hline Premium on energy & $10 \%$ & 37.2 & 43.1 & 80.3 \\
& $50 \%$ & 39.6 & 40.3 & 79.9 \\
& $10 \%$ & 48.1 & 32.1 & 80.2 \\
Premium on capacity & $50 \%$ & 48.2 & 31.4 & 79.6 \\
\hline
\end{tabular}

\footnotetext{
${ }^{4}$ Average wholesale prices are the same for RTP and FRP consumers. More precisely, RTP consumers face a consumption-weighted average real-time price, which corresponds to the shadow price of equation (4) in the appendix. This perfectly resembles the flat-rate price $\bar{p}$.
} 
Because of lower wholesale prices, the market value of RES is also substantially lower in case of a premium on energy as compared to a premium on capacity (Table 3). In general, wind power has slightly higher market values than PV because the merit-order effect related to simultaneous production is less pronounced. Market values generally increase with higher RTP shares as more consumers are able to increase their consumption in periods with high RES availability, driving up wholesale prices in these hours. This is the intuitive effect of flexibility as for example quantified by Mills \& Wiser(2015).

Table 3: Comparison of market values [€/MWh]

\begin{tabular}{lccc}
\hline & $\boldsymbol{\alpha}$ & Wind power & PV \\
\hline \multirow{2}{*}{ Premium on energy } & $10 \%$ & 7.4 & 4.4 \\
& $50 \%$ & 10.8 & 8.7 \\
\multirow{3}{*}{ Premium on capacity } & $10 \%$ & 29.5 & 27.2 \\
& $50 \%$ & 29.9 & 27.7 \\
\hline
\end{tabular}

But why are the differences with respect to prices and market values between the two instruments so extreme when at the same time differences in capacity and generation are so marginal? The explanation is that negative prices result from additional consumption of the RTP consumers alone, as FRT consumers only react to average prices and thus do not consume more in times RES supply is abundant. Because the RTP share is relatively low in the base case and demand is relatively inelastic, little additional consumption in hours of negative prices (560 MW) drives prices down considerably in case of the premium on energy.

\subsection{Welfare effects}

As regards total welfare - i.e. consumer surplus - there are notable differences between the two RES support instruments. Shifting from a capacity-based support instrument to an energy-based one leads to welfare gains between 27 and 108 mil $€$ for the cases considered here (Table 4). ${ }^{5}$ This outcome is driven by large surplus gains of RTP consumers which benefit from additional consumption in times of high RES availability. In contrast, FRP consumers are worse off when shifting from capacity-based to energy-based RES support, as these cannot increase their consumption during low-price periods, but at the same time face higher levies. In other words, FRP consumers partly subsidize the welfare gains of RTP consumers. It should be noted that the premium on energy

\footnotetext{
${ }^{5}$ The values in Table 4 are calculated by subtracting the respective consumer surpluses of the capacity-based system from those of the energy-based one.
} 
leads to higher welfare outcomes than the capacity-based premium, although market values are markedly lower in this case. Accordingly, focusing on high market values of RES is not sufficient from a welfare perspective in a setting with RES support instruments and a demand-side that is at least partly responsive to real-time prices.

Table 4: Consumer surplus changes between premium on capacity and premium on energy [mil $€$ ]

\begin{tabular}{cccc}
\hline$\alpha$ & FRP consumers & RTP consumers & All consumers \\
\hline $10 \%$ & -27.4 & 54.2 & 26.8 \\
$20 \%$ & -45.8 & 96.9 & 51.0 \\
$30 \%$ & -56.0 & 128.8 & 72.9 \\
$40 \%$ & -58.3 & 150.4 & 92.1 \\
$50 \%$ & -55.0 & 163.4 & 108.4 \\
\hline
\end{tabular}

Another consequence of the aforementioned differences in prices is that consumers do benefit differently from increasing RTP shares, which can be unveiled by decomposing consumer surplus changes (Table 5). Common to both instruments is that existing RTP consumers (column $\Delta C S^{R T P}$ ), i.e. consumers that already faced an RTP tariff before $\alpha$ was increased, (almost) always lose surplus when $\alpha$ is increased, while remaining FRP and switching consumers (columns $\triangle C S^{F R P}$ and $\triangle C S^{S W I T C H}$ ) gain surplus. Likewise, the main benefits accrue for switchers under both instruments, while gains slightly decrease with increasing $\alpha$. In fact, switchers incur most of the overall welfare gains. Notably under a market premium on energy, both total surplus gains and switcher gains are higher, whereas under a premium on capacity switchers benefit less (and flat-rate consumers somewhat more). The difference in switcher surplus gains is around $40 \%$ for every gradual increase of $\alpha$, while the difference in overall welfare gains is only around $14 \%$. The apparent explanation is that switching from FRP to RTP is more beneficial under a premium on energy because of additional consumption in times when wholesale prices are negative.

Table 5: Consumer surplus changes between different RTP shares [mil €]

\begin{tabular}{|c|c|c|c|c|}
\hline \multicolumn{5}{|c|}{ Market premium on energy } \\
\hline$\Delta \alpha$ & $\Delta C S^{F R P}$ & $\Delta C S^{R T P}$ & $\Delta C S^{S W I T C H}$ & $\Delta C S^{S U M}$ \\
\hline $10 \%->20 \%$ & 39.0 & -29.5 & 184.6 & 194.1 \\
\hline $20 \%->30 \%$ & 28.3 & -24.7 & 167.4 & 171.0 \\
\hline $30 \%->40 \%$ & 23.5 & -21.8 & 156.0 & 157.7 \\
\hline $40 \%->50 \%$ & 19.8 & -19.4 & 147.3 & 147.7 \\
\hline
\end{tabular}




\begin{tabular}{|c|c|c|c|c|}
\hline \multicolumn{5}{|c|}{ Market premium on capacity } \\
\hline$\Delta \alpha$ & $\Delta C S^{F R P}$ & $\Delta C S^{R T P}$ & $\Delta C S^{S W I T C H}$ & $\Delta C S^{S U M}$ \\
\hline $10 \%->20 \%$ & 60.4 & -23.7 & 133.1 & 169.9 \\
\hline $20 \%->30 \%$ & 44.2 & -13.8 & 118.7 & 149.1 \\
\hline $30 \%->40 \%$ & 33.9 & -5.8 & 110.4 & 138.5 \\
\hline $40 \%$-> 50\% & 26.2 & 0.3 & 104.9 & 131.4 \\
\hline
\end{tabular}

These results have important implications for the deployment of flexibility. The incentive to switch from FRP to RTP are markedly higher under a market premium on energy that under a market premium on capacity. Hence consumers may in general be more willing to switch. Likewise, any efforts related to the realization of increasing RTP shares, be it infrastructure investments or institutional adjustments, are more rewarding under an energy-related premium. Of course if consumers will eventually decide to switch, and if they actually have the possibility to do so, also depends on many factors. In particular, they will weigh benefits against costs and if costs are higher no switching will take place. We do leave out costs here because we are not concerned about the optimal level of flexibility, but only about additional benefits in line with Alcott (2012).

\subsection{Sensitivity analysis}

The effects discussed obviously depend on the assumed price elasticity of demand, which in the base case is very inelastic. Hence a major question is how effects will change under the assumption of higher elasticity. First we double the assumed price elasticity at the reference point $(\varepsilon=-0.10)$. As expected, consumer surplus changes (Table 6) in this case are considerably higher. In particular, surplus gains for switchers rise by $55-80 \%$ compared to the base case, again with highest gains for low values of $\alpha$. Accordingly, consumers have even higher incentives to switch when demand is more elastic. Furthermore, because of higher RES utilization overall support payments are 6-7\% lower: 13.1 bn $€$ in case of the premium on capacity and 17.8 bn $€$ in case of the premium on energy respectively. These effects are also reflected in a "flattened" price duration curve: a higher elasticity reduces peak prices and at the same time lifts the negative price plateau (Figure 2).

Table 6: Consumer surplus changes between different RTP shares [mil $€$ ] for sensitivity with $\varepsilon=-\mathbf{0 . 1 0}$

\begin{tabular}{|c|c|c|c|c|}
\hline \multicolumn{5}{|c|}{ Market premium on energy } \\
\hline$\Delta \alpha$ & $\Delta C S^{F R P}$ & $\Delta C S^{R T P}$ & $\triangle C S^{S W I T C H}$ & $\Delta C S^{S U M}$ \\
\hline $10 \%->20 \%$ & 75.7 & -55.9 & 331.7 & 351.5 \\
\hline $20 \%->30 \%$ & 73.6 & -61.1 & 291.7 & 304.2 \\
\hline $30 \%->40 \%$ & 82.3 & -76.0 & 255.8 & 262.1 \\
\hline $40 \%->50 \%$ & 62.5 & -60.5 & 227.0 & 228.9 \\
\hline
\end{tabular}




\begin{tabular}{|c|c|c|c|c|}
\hline \multicolumn{5}{|c|}{ Market premium on capacity } \\
\hline$\Delta \alpha$ & $\Delta C S^{F R P}$ & $\Delta C S^{R T P}$ & $\Delta C S^{S W I T C H}$ & $\Delta C S^{S U M}$ \\
\hline $10 \%->20 \%$ & 111.2 & -35.8 & 231.7 & 307.1 \\
\hline $20 \%->30 \%$ & 91.0 & -25.2 & 205.2 & 270.9 \\
\hline $30 \%->40 \%$ & 91.2 & -32.9 & 181.2 & 239.5 \\
\hline $40 \%->50 \%$ & 67.5 & -15.4 & 162.2 & 214.3 \\
\hline
\end{tabular}

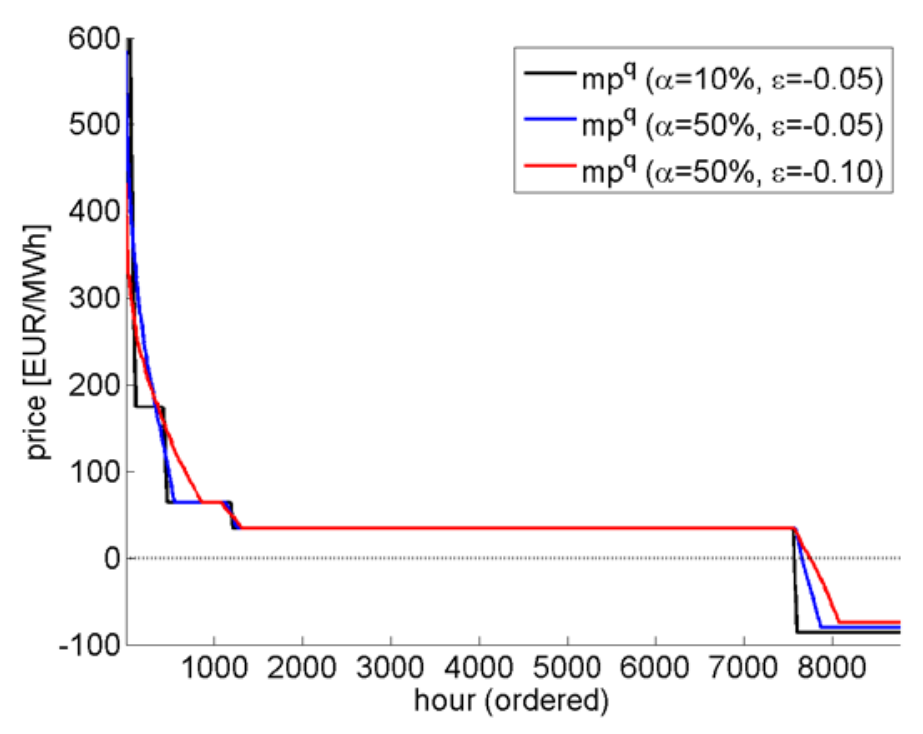

Figure 2: Price duration curve for $\alpha=0.5$

As a second sensitivity we look at a different functional form of demand, namely an isoelastic function. A very important difference between these forms in this context is that for the isoelastic function demand grows to infinity when the price approaches zero and thus prices can in general not become negative. Moreover, in case of an isoelastic function demand is much more responsive when prices are low compared to a linear function where point elasticities are close to zero near the point where the price becomes zero. In consequence, consumption in times of high RES supply will be much higher and thus curtailment can never occur in case there is at least one RTP consumer. So isoelastic demand essentially resembles a system with unlimited capacity of consumers to take up surplus generation. In such a system, which is obviously hypothetical, it can be expected that the difference between the two instruments gets smaller. In fact, model results broadly confirm that view. This indicates that the size of all effects identified above depends on the demand function in the specific market, and in particular how consumers react to very low prices. 


\section{Discussion of limitations}

In this section, we briefly discuss some limitations of the model and indicate the direction in which

these limitations may distort results.

While focusing on increased demand-side flexibility, we neglect other flexibility options such as dispatchable renewable power sources, power storage, and international trade. In particular, storage and international trade will increase demand in times of high RES generation and low prices, while the opposite is true in times of high residual demand. We thus tend to overestimate the fluctuations of residual load and spot prices, and accordingly also overestimate the value of increased demandside flexibility.

A similar reasoning applies to the issue of scaling up historic renewable feed-in time-series. While this method is often applied in the literature, it disregards potential future smoothing effects related to changes in the design and the spatial distribution of renewable generators (see Schill 2014). This may contribute to an overestimation of the value of DSR.

Another distortion in the same direction is likely to be caused by our greenfield assumption. The optimized power plant portfolio modeled here may include lower capacities of base- and mid-load technologies that have high fixed and low variable costs, compared to a brownfield scenario in which some of these capacities already exist. Power prices may thus tend to be too high in many hours, such that the value of increased DSR may be overestimated.

The opposite is true for another limitation of the model, i.e. disregarding flexibility restrictions of thermal generators such as start-up and ramping costs. Neglecting such costs may thus result in an underestimation of the value of demand-side flexibility. In another model-based analysis, we show that the relevance of start-up costs may not diminish in medium-run scenarios of the German energy transition (Schill et al. forthcoming).

\section{Conclusions}

In this paper, we analyze intricate interactions between instruments for renewable support schemes and the benefits of increasing RTP shares in the context of fluctuating RES and binding RES targets. This interaction takes place via power prices, i.e. support instruments have different impacts on power prices which in turn affect the benefits of and the incentives for increased demand-side flexibility. Several findings of our analysis regarding this interaction might be helpful for policy makers when making combined decisions on long-term policies related to RES and flexibility deployment. 
A first general finding relates to power prices. Assuming a linear demand function, the two market premiums do not differ much with respect to overall capacities, dispatch and overall retail prices. But there are considerable differences regarding wholesale prices and support levies. The reason is that lower market values of fluctuating RES in case of the premium on energy, which are related to negative prices, must necessarily be compensated by higher levies in order to assure that - given a fixed RE target - total costs are covered. That said, the fact that the RE levy is considerably higher in case of a premium on energy may have important political economy implications. In particular, if total costs of support are higher, the question of exemptions from the levy for large consumers may be of more concern to policy makers in face of their regressive character.

The second main finding relates to welfare outcomes. Overall surplus is higher in case of a market premium on energy as compared to a capacity-related premium, as this allows RTP consumers to increase their consumption in periods of high RES availability. Moreover, considerable efficiency differences accrue when looking at the benefits of increasing RTP shares. Total consumer surplus increases and thus welfare gains are considerably higher for the premium on energy, and generally highest for switchers. Assuming that these surplus gains will be fully internalized by the respective consumers, there are equally higher incentives for consumers to move from a flat-rate tariff to RTP under an energy-based premium. From a policy perspective, taking measures to increase RTP shares is accordingly more rewarding if coordinated with an energy-based support scheme. Furthermore, surpluses roughly double when demand is assumed to be twice as elastic at the reference point. This underlines that consumer preferences play a very important role beyond mere price effects. However, crucial for the difference between the instruments is the elasticity of demand when prices are very low.

Ultimately, our analysis of the coordination between RES support schemes and increased DSR puts the widespread notion that higher market values are always a good thing into perspective: in the context of binding RES targets, which are to be achieved with dedicated support instruments that rely on equally attributed levies, and in the presence of non-negligible shares of RTP consumers, negative prices and low market values of RES are not necessarily bad news. In contrast, negative prices that are related to the support instrument may be regarded as a source of welfare gains. Likewise, increasing the market value of fluctuating RES should not be considered a policy goal per se, as lower market values may well go along with higher total welfare. 


\section{References}

Agora Energiewende, 2015. Aktionsplan Lastmanagement, Available at: http://www.agoraenergiewende.de/fileadmin/Projekte/2014/aktionsplanlastmanagement/Agora_Aktionsplan_Lastmanagement_web.pdf.

Agora Energiewende, 2014. Erneuerbare-Energien-Gesetz 3.0. Konzept einer strukturellen EEGReform auf dem Weg zu einem neuen Strommarktdesign (Langfassung)., Available at: http://www.agora-

energiewende.de/fileadmin/downloads/publikationen/Impulse/EEG_30/Agora_Energiewend e_EEG_3_0_LF_web.pdf.

Allcott, H., 2012. Real-Time Pricing and Electricity Market Design, Available at: https://files.nyu.edu/ha32/public/research/Allcott\%202012\%20-\%20Real-

Time\%20Pricing\%20and\%20Electricity\%20Market\%20Design.pdf.

BMWi, 2015a. Ausschreibungen für die Förderung von Erneuerbare-Energien-Anlagen. Eckpunktepapier, Available at:

http://www.bmwi.de/BMWi/Redaktion/PDF/Publikationen/ausschreibungen-foerderungerneuerbare-energien-anlage, property=pdf, bereich=bmwi2012, sprache=de, $r w b=$ true.pdf.

BMWi, 2015b. Ein Strommarkt für die Energiewende, Weißbuch, Available at: http://www.bmwi.de/BMWi/Redaktion/PDF/Publikationen/weissbuch, property=pdf, bereich $=$ bmwi2012, sprache=de, rwb=true.pdf.

Borenstein, S. \& Holland, S., 2005. On the Efficiency of Competitive Electricity Markets with TimeInvariant Retail Prices. The RAND Journal of Economics, 36(3), pp.469-493.

Boute, A., 2012. Promoting renewable energy through capacity markets: An analysis of the Russian support scheme. Energy Policy, 46, pp.68-77.

Bushnell, J.B., 2011. Building Blocks: Investment in Renewable and Nonrenewable Technologies. EUI RSCAS WP 2011/53, Available at: http://cadmus.eui.eu/bitstream/handle/1814/19421/RSCAS_2011_53.pdf?sequence=1.

Cappers, P. et al., 2012. An assessment of the role mass market demand response could play in contributing to the management of variable generation integration issues. Energy Policy, 48, pp.420-429.

Edenhofer, O. et al., 2013. On the economics of renewable energy sources. Energy Economics, 40, pp.S12-S23.

Enervis \& BET, 2013. Ein zukunftsfähiges Energiemarktdesign für Deutschland, Available at: www.vku.de/fileadmin/get/?24103/EMD_Gutachten_Langfassung.pdf.

European Commission, 2015. Launching the public consultation process on a new energy market design. $\operatorname{COM}(2015) \quad 340$ final, Available http://ec.europa.eu/energy/sites/ener/files/documents/1_EN_ACT_part1_v11.pdf.

Faruqui, A. \& Sergici, S., 2010. Household response to dynamic pricing of electricity: a survey of 15 experiments. Journal of Regulatory Economics, 38(2), pp.193-225. 
Gambardella, C., Pahle, M. \& Schill, W.P., forthcoming. Welfare Effects of Dynamic Retail Pricing In The Presence of Variable Renewable Energy Supply and Planning Reserve Margin Constraints, mimeo, PIK Potsdam.

Gawel, E. \& Purkus, A., 2013. Die Marktprämie im EEG 2012: Ein sinnvoller Beitrag zur Markt- und Systemintegration erneuerbarer Energien? Zeitschrift für Energiewirtschaft, 37(1), pp.43-61.

Green, R. \& Vasilakos, N., 2010. Market behaviour with large amounts of intermittent generation. Energy Policy, 38(7), pp.3211-3220.

Hirth, L., 2013. The market value of variable renewables. Energy Economics, 38, pp.218-236.

De Jonghe, C., Hobbs, B.F. \& Belmans, R., 2014. Value of Price Responsive Load for Wind Integration in Unit Commitment. IEEE Transactions on Power Systems, 29(2), pp.675-685.

Joskow, P.L., 2011. Comparing the Costs of Intermittent and Dispatchable Electricity Generating Technologies. American Economic Review, 101(3), pp.238-241.

Klessmann, C., Nabe, C. \& Burges, K., 2008. Pros and cons of exposing renewables to electricity market risks $-\mathrm{A}$ comparison of the market integration approaches in Germany, Spain, and the UK. Energy Policy, 36(10), pp.3646-3661.

Lang, C. \& Okwelum, E., 2015. The mitigating effect of strategic behavior on the net benefits of a direct load control program. Energy Economics, 49, pp.141-148.

Lund, P.D. et al., 2015. Review of energy system flexibility measures to enable high levels of variable renewable electricity. Renewable and Sustainable Energy Reviews, 45, pp.785-807.

Mills, A.D. \& Wiser, R.H., 2015. Strategies to mitigate declines in the economic value of wind and solar at high penetration in California. Applied Energy, 147, pp.269-278.

Nicolosi, M., 2010. Wind power integration and power system flexibility-An empirical analysis of extreme events in Germany under the new negative price regime. Energy Policy, 38(11), pp.7257-7268.

Pahle, M. et al., 2013. Investments in Imperfect Power Markets under Carbon Pricing: A Case Study Based Analysis. The Energy Journal, 13(4), pp.199-227.

Pahle, M. \& Schweizerhof, H., 2015. Time for tough love: Towards gradual risk transfer to renewables in Germany.

Perez-Arriaga, I.J. \& Batlle, C., 2012. Impacts of Intermittent Renewables on Electricity Generation System Operation. Economics of Energy \& Environmental Policy, 1(2). Available at: http://www.iaee.org/en/publications/eeeparticle.aspx?id=17 [Accessed August 24, 2015].

Pineau, P.-O. \& Murto, P., 2003. An Oligopolistic Investment Model of the Finnish Electricity Market. Annals of Operations Research, 121, pp.123-148.

Schill, W.P., 2014. Residual load, renewable surplus generation and storage requirements in Germany. Energy Policy, 73, pp.65-79.

Schill, W.P., Pahle, M. \& Gambardella, C., forthcoming. On the Relevance of Start-up Costs for Markets with Increasing Shares of Renewables, mimeo, DIW Berlin. 
Schröder, A. et al., 2013. Current and Prospective Costs of Electricity Generation until 2050. DIW Data Documentation 68., Available at: http://www.diw.de/documents/publikationen/73/diw_01.c.424566.de/diw_datadoc_2013068.pdf.

De Vos, K., 2015. Negative Wholesale Electricity Prices in the German, French and Belgian Day-Ahead, Intra-Day and Real-Time Markets. The Electricity Journal, 28(4), pp.36-50.

Wolak, F.A., 2011. Do Residential Customers Respond to Hourly Prices? Evidence from a Dynamic Pricing Experiment. American Economic Review, 101(3), pp.83-87.

Zerrahn, A. \& Schill, W.P., 2015a. A Greenfield Model to Evaluate Long-Run Power Storage Requirements for High Shares of Renewables. DIW Discussion Paper 1457, Available at: http://www.diw.de/documents/publikationen/73/diw_01.c.498475.de/dp1457.pdf.

Zerrahn, A. \& Schill, W.P., 2015b. On the representation of demand-side management in power system models. Energy, 84, pp.840-845. 


\section{Appendix}

Table 7: Sets, indices, parameter and variables

\begin{tabular}{|c|c|c|}
\hline Symbol & Description & Unit \\
\hline \multicolumn{3}{|c|}{ Sets and indices } \\
\hline$t \in T$ & Time periods & Hours \\
\hline$i \in I$ & Generation technologies & \\
\hline$I R \subset I$ & Renewable technologies & \\
\hline \multicolumn{3}{|c|}{ Parameters } \\
\hline$\alpha$ & Share of RTP consumers & \\
\hline$a v_{i, t}$ & Hourly availability of fluctuating renewables & \\
\hline$\varepsilon$ & Price elasticity of demand at reference point & \\
\hline$f c_{i}$ & Fixed generation costs & $€ / M W$ \\
\hline$m$ & Slope of linear demand curve & $€ /(\mathrm{MWh})^{2}$ \\
\hline$m c_{i}$ & Marginal generation costs & $€ / \mathrm{MWh}$ \\
\hline$p 0_{t}$ & Interception of linear demand curve & $€ / M W h$ \\
\hline $\boldsymbol{\theta}$ & Targeted renewable share & \\
\hline \multicolumn{3}{|c|}{ Variables } \\
\hline $\boldsymbol{K}_{\boldsymbol{i}}$ & Generation capacity & MW \\
\hline$\lambda_{i, t}$ & Shadow price of capacity constraint & $€ / M W$ \\
\hline $\boldsymbol{l}$ & Levy to finance RES support & $€ / \mathrm{MWh}$ \\
\hline$m p_{i}^{c}$ & Market premium on capacity & $€ / \mathrm{MW}$ \\
\hline$m p^{q}$ & Market premium on energy & $€ / \mathrm{MWh}$ \\
\hline$\overline{\boldsymbol{p}}$ & Flate-rate retail price & $€ / \mathrm{MWh}$ \\
\hline $\mathbf{p}_{\mathrm{t}}$ & Wholesale price & $€ / M W h$ \\
\hline $\mathbf{q}_{i, t}$ & Hourly generation & $\mathrm{MWh}$ \\
\hline$Q_{t}$ & Hourly demand & $\mathrm{MWh}$ \\
\hline$w f$ & Welfare & $€$ \\
\hline
\end{tabular}


In the following, we provide the full analytical formulation of the problem for the case with a linear demand function. Equation (1) is the upper level problem of the MPEC, i.e. the regulator maximize welfare by choosing an appropriate market premium on energy $m p^{q}$ or capacity $m p_{i}^{c}$. Equation (1) is maximized subject to (2)-(8). Equation (2) ensures that the specified renewable share $\theta$ has to be reached. Equations (3)-(8) constitute the lower level problem of the MPEC, i.e. the MCP of the market equilibrium for a given level of RES support. The market clearing condition (3) ensures that supply always matches demand, which is composed of both RTP consumers and flat-rate consumers. (4) is the zero profit condition on the retail market. (5a) and (5b) are the first order conditions of generators with respect to generation levels. (5a) applies to the case of an energy-based market premium, and (5b) to the case of capacity-based RES support. Likewise, (6a) and (6b) are the first order conditions with respect to capacity, depending on the support instrument. Equation (7) reflects generation capacity constraints. Finally, equations (8a) an (8b) are required to make sure that the market premiums are financed by the levy. Again, (8a) applies to the energy-based premium, whereas (8b) applies to the capacity-based one.

$$
\begin{gathered}
\max w f=\sum_{T}\left[\alpha\left(\frac{\left(\mathrm{p}_{\mathrm{t}}+\text { levy }\right)^{2}}{2 m}-\frac{p 0_{t}-\mathrm{p}_{\mathrm{t}}}{m}\right)+(1-\alpha)\left(\frac{(\bar{p}+\text { levy })^{2}}{2 m}-\frac{p 0_{t}-\bar{p}}{m}\right)\right] \\
-\sum_{I, T} m c_{i} \mathrm{q}_{i, t}-\sum_{I} f c_{i} K_{i} \\
\sum_{I \in I R, T} \mathrm{q}_{i, t}=\theta \sum_{I, T} \mathrm{q}_{i, t} \\
0=\sum_{I, T} \mathrm{q}_{i, t}-\alpha \frac{\mathrm{p}_{\mathrm{t}}+l-p 0_{t}}{m}-(1-\alpha) \frac{\bar{p}+l-p 0_{t}}{m}, \mathrm{p}_{\mathrm{t}} \text { free } \\
0=\sum_{T}\left(\left(\bar{p}-\mathrm{p}_{\mathrm{t}}\right)(1-\alpha) \frac{\bar{p}+l-p 0_{t}}{m}\right), \bar{p} \text { free }
\end{gathered}
$$




$$
\begin{array}{cc}
0 \leq m c_{i}-m p^{q}+\lambda_{i, t}-\mathrm{p}_{\mathrm{t}} \perp \mathrm{q}_{i, t} \geq 0 & \forall i \in I R, t \\
0 \leq m c_{i}+\lambda_{i, t}-\mathrm{p}_{\mathrm{t}} \perp \mathrm{q}_{i, t} \geq 0 & \forall i \notin I R, t \\
0 \leq m c_{i}+\lambda_{i, t}-\mathrm{p}_{\mathrm{t}} \perp \mathrm{q}_{i, t} \geq 0 & \forall i, t \\
0 \leq f c_{i}-\sum_{T} \lambda_{i, t} a v_{i, t} \perp K_{i} \geq 0 &
\end{array}
$$

$$
\begin{array}{cc}
0 \leq f c_{i}-m p_{i}^{c}-\sum_{T} \lambda_{i, t} a v_{i, t} \perp K_{i} \geq 0 & \forall i \in I R \\
0 \leq f c_{i}-\sum_{T} \lambda_{i, t} a v_{i, t} \perp K_{i} \geq 0 & \forall i \notin I R
\end{array}
$$

$$
0 \leq K_{i} a v_{i, t}-\mathrm{q}_{i, t} \perp \lambda_{i, t} \geq 0 \quad \forall i, t
$$

$$
0=l-\frac{\sum_{I \in I R, T} \mathrm{q}_{i, t} m p^{q}}{\sum_{I, T} \mathrm{q}_{i, t}}, l \text { free }
$$

$$
\begin{gathered}
0=l-\frac{\sum_{I} K_{i} m p_{i}^{c}}{\sum_{I, T} \mathrm{q}_{i, t}}, \text { lfree } \\
0=l-\frac{\sum_{I} K_{i}}{\sum_{I, T} \mathrm{q}_{i, t}}, \text { lfree }
\end{gathered}
$$

